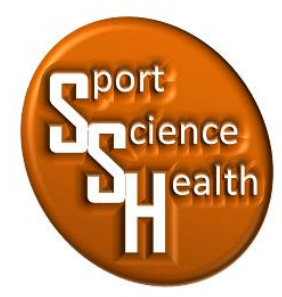

ISSN 2715-3886

\title{
Pengembangan Perangkat Pembelajaran Gerak Dasar Lari Berbasis Aplikasi Articulate Storyline
}

\author{
Achmad Rizal Yuliansyah ${ }^{1 \star}$, Lokananta Teguh Hari Wiguno², Ari Wibowo Kurniawan³, \\ Mu'arifin ${ }^{4}$ \\ 1,2,3,4Jurusan Pendidikan Jasmani, Kesehatan dan Rekreasi, Fakultas IImu Keolahragaan, \\ Universitas Negeri Malang, Jalan Semarang No 5, Malang, Jawa Timur, 65145, Indonesia \\ *Penulis koresponden: yuliansyahrizal11@gmail.com, 085776403302
}

Artikel diterima: 4 Maret 2021; direvisi: 16 April 2021; disetujui: 21 April 2021

\begin{abstract}
The purpose of this research is to develop basic motion learning tools for running based on the articulate storyline application. In the analysis technique carried out in this study using quantitative descriptive analysis using percentages. test results by learning experts get a percentage of $94 \%$, elementary school game expert test results get a percentage of $96 \%$, validation tests by Physical Education, Sports and Health experts get a percentage of $90 \%$, media expert test results get a percentage of $96 \%$, the athletic expert test results get a percentage of $93 \%$, the test results in the small group get a percentage of $89 \%$ and the large group test results get a percentage of $86 \%$, and that means the overall test results by several experts as well as product tests for small groups and large groups in the product development of basic motion learning tools for running based on the articulate storyline application has very valid criteria and is suitable for use. It can be concluded that the product of developing basic motion learning tools for running based on the articulate storyline application is feasible to use and can be used as a learning support for the subject of Physical Education, Sports and Health in grade IV SD for basic motion learning material for running.
\end{abstract}

Keyword: learning device, Basic motion running, Articulate storyline application

Abstrak: Tujuan dari penelitian ini yaitu untuk mengembangkan perangkat pembelajaran gerak dasar lari berbasis aplikasi articulate storyline. Pada teknik analisis yang dilakukan dalam penelitian ini menggunakan analisis deskriptif kuantitatif menggunakan persentase. hasil uji oleh ahli pembelajaran mendapatkan hasil persentase sebesar 94\%, hasil uji ahli permainan Sekolah Dasar mendapatkan hasil persentase sebesar 96\%, uji validasi oleh ahli Pendidikan Jasmani, Olahraga dan Kesehatan diperoleh hasil persentase sebesar $90 \%$, hasil uji ahli media mendapatkan hasil persentase $96 \%$, hasil uji ahli atletik mendapatkan hasil persentase $93 \%$, Hasil uji pada kelompok kecil diperoleh persentase $89 \%$ dan hasil uji kelompok besar diperoleh persentase sebesar $86 \%$, dan artinya keseluruhan hasil uji oleh beberapa ahli serta uji produk untuk kelompok kecil dan kelompok besar pada produk pengembangan perangkat pembelajaran gerak dasar lari berbasis aplikasi articulate storyline mendapatkan kriteria sangat valid dan layak digunakan. Maka dapat disimpulkan bahwa produk pengembangan perangkat pembelajaran gerak dasar lari berbasis aplikasi articulate storyline ini layak digunakan dan dapat dijadikan sebagai penunjang pembelajaran pada mata pelajaran Pendidikan Jasmani Olahraga dan Kesehatan kelas IV SD untuk materi pembelajaran gerak dasar lari.

Kata kunci: perangkat pembelajaran, gerak dasari lari, aplikasi articulate storyline 


\section{PENDAHULUAN}

Pendidikan jasmani merupakan suatu mata pelajaran yang di ajarkan di sekolah sebagai media untuk memacu perkembangan motorik, sikap sportif, kemampuan fisik, pengetahuan, kebiasaan hidup sehat dan pembentukan karakter meliputi (mental, emosional, sosial, serta spiritual) untuk mencapai sebuah tujuan pendidkan nasional (Adi \& Fathoni, 2019, 2020a, 2020b). Menurut Pahliwandari, R (2017) pendidikan Jasmani atau yang lebih dikenal dengan Penjas (Dikjas) merupakan salah satu mata pelajaran formal yang telah diberikan mulai dari sekolah dasar hingga sekolah menengah. Sedangkan menurut Mustafa, P.S. \& Dwiyogo, W.D, (2020) menjelaskan bahwa pendidikan jasmani merupakan bagian dari pendidikan yang mengembangkan kemampuan melalui gerak sehingga dapat mencapai kesehatan serta tujuan pendidikan yang diharapkan yaitu mencakup pengetahuan, keterampilan, dan sikap. Dengan demikian guru penjas perlu memahami tujuan dari pendidikan jasmani agar pembelajaran gerak menjadi berkembang sesuai dengan target yang dicapai. Oleh kerena itu dapat disimpulkan bahwa pendidikan jasmani merupakan proses pendidikan yang lebih berfokus kepada aktivitas fisik, gerak dan emosional peserta didik. Pendidikan jasmani juga menekankan agar terjadinya perubahan yang lebih baik dari peserta didik baik jasmani maupun rohaninya serta mencapai perkembangan pendidikan jasmani dari segi fisik, gerak, mental, dan sosial (Adi \& Fathoni, 2020; Fathoni, 2018). Dalam materi pendidikan jasmani, olahraga dan kesehatan terdapat bebarapa materi pembelajaran di dalamnya salah satu materi yang ada dalam pendidikan jasmani, olahraga dan Kesehatan disekolah adalah materi gerak dasar lari.

Salah satu materi gerak dasar lari pada umumnya sangat erat kaitannya berhubungan dengan aktivitas fisik dan gerak siswa, Lari merupakan gerak dasar dari semua cabang olahraga yang dilakukan dengan cara badan bergerak ke depan karena dengan adanya dari gaya tolakan ke belakang terhadap tanah. Permainan yang melibatkan gerakan berlari sangat diminati oleh siswa. Peserta didik harus memahami materi pembelajaran gerak dasar berlari dan dapat mempraktikkannya dengan benar. Karena materi gerak dasar lari terdapat dalam kompetensi kognitif dan psikomotorik yang dirumuskan di Kompetensi Inti (KI) dan Kompetensi Dasar (KD) yang sudah diajarkan di jenjang Sekolah Dasar (SD) kelas IV yang dirumuskan sebagai berikut.

Tabel 1. Kompetensi Inti \& Kompetensi Dasar Pendidikan Jasmani dan Kesehatan Kelas IV (Permendikbud No 37 Tahun 2018)

\begin{tabular}{|c|c|}
\hline Kompetensi Inti Pengetahuan Kelas IV & Kompetensi Inti Keterampilan Kelas IV \\
\hline $\begin{array}{l}\text { 3. Memahami pengetahuan faktual dengan } \\
\text { cara mengamati dan menanya berdasarkan } \\
\text { rasa ingin tahu tentang dirinya, makhluk } \\
\text { ciptaan Tuhan dan kegiatannya, dan } \\
\text { benda-benda yang dijumpainya di rumah, di } \\
\text { sekolah dan tempat bermain }\end{array}$ & $\begin{array}{l}\text { 4. Menyajikan pengetahuan factual dalam } \\
\text { bahasa yang jelas, sistematis dan logis, } \\
\text { dalam karya yang estetis, dalam gerakan } \\
\text { yang mencerminkan anak sehat, dan dalam } \\
\text { tindakan yang mencerminkan perilaku anak } \\
\text { beriman dan berakhlak mulia }\end{array}$ \\
\hline Kompetensi Pengetahuan Kelas IV & Kompetensi Keterampilan Kelas IV \\
\hline $\begin{array}{l}\text { 3.3 Memahami variasi gerak dasar jalan, } \\
\text { lari, lompat, dan lempar melalui } \\
\text { permainan/olahraga yang dimodifikasi dan } \\
\text { atau olahraga tradisional. }\end{array}$ & $\begin{array}{l}\text { 4.3 Mempraktikkan variasi pola dasar jalan, } \\
\text { lari, lompat, dan lempar melalui } \\
\text { permainan/olahraga yang dimodifikasi dan } \\
\text { atau olahraga tradisional. }\end{array}$ \\
\hline
\end{tabular}

Hal tersebut dapat digunakan seorang pendidik sebagai pertimbangan dalam meningkatan kemampuan untuk mengikuti pembinaan dalam mengembangkan pembelajaran terutama gerak dasar lari. Menurut Semakur (2020) menyatakan bahwa keterampilan gerak dasar berlari dapat diartikan sebagai kemampuan untuk melaksanakan tugas-tugas gerak lari secara baik dan benar. Dalam pendidikan jasmani, olahraga dan kesehatan olahraga lari sudah diajarkan sejak SD bahkan sudah sering diperlombakan. Pada dasarnya struktur dan karakteristik pola gerak dalam atletik terdapat pada tiga hal pokok, yaitu (1) lari termasuk jalan, (2) lompat, dan (3) lempar. Sedangkan menurut Aryadi, D. \& Daulay, D.E, (2019) lari adalah nomor atletik yang menjadi dasar dari hampir semua cabang olahraga yang ada saat ini, paling tidak dalam hal pemanasan (warming up) lari merupakan salah satu nomor atletik yang paling penting, karena sebagian besar cabang olahraga terdapat unsur lari didalamnya. Sedangkan secara teknis, gerak dasar lari dapat dibedakan atas beberapa macam substansi, yaitu, lari santai (jogging), lari cepat (sprint), lari jarak menengah, dan lari jarak jauh serta marathon. Oleh karena itu dapat disimpulkan bahwa lari adalah gerakan berpindah tempat atau 
memindahkan tubuh dari satu titik ke titik lainnya dengan cara melangkah menggunakan kaki secara cepat dan bergantian.

Dunia pendidikan telah mengalami banyak kemajuan di era globalisai. Belakang ini media pembelajaran banyak digunakan dalam meningkatkan mutu pembelajaran. Tujuannya adalah menciptakan suatu Sumber Daya Manusia (SDM) yang dapat berdaya saing tinggi, berkualitas, serta melek akan teknologi. Guru memiliki peranan penting dalam proses pembelajaran. Guru berfungsi menjadi seorang pemimpin atau pengajar, sedangkan seorang siswa berperan menjadi pelajar atau individu yang sedang belajar. Proses belajar mengajar akan efektif dan efesien apabila siswa cenderung aktif saat mengikuti proses pembelajaran, sehingga pembelajaran akan terfokus pada siswa dan guru akan menjadi seorang fasilitator siswa dalam belajar. Oleh karena itu, guru harus menguasai berbagai macam strategi dan metode pembelajaran guna meningkatkan kualitas pembelajaran.

Perkembangan IImu Pengetahuan Teknologi dan Komunikasi (IPTEK) menuntut guru untuk melaksanakan pekerjaan secara professional (Kristiono, Dwiyogo, \& Hariadi, 2019; Masgumelar, Dwiyogo, \& Nurrochmah, 2019; Pambudi, Winarno, \& Dwiyogo, 2019; Rodriquez, Dwiyogo, \& Supriyadi, 2020). Guru dapat memanfaatkan berbagai media pembelajaran saat proses belajar mengajar berlangsung (Christianto \& Dwiyogo, 2020; Dwiyogo \& Radjah, 2020; Kurniawan, Winarno, \& Dwiyogo, 2018; Manalu, Dwiyogo, \& Heynoek, 2020). Sehingga mampu membangkitkan rasa keingintahuan peserta didik pada materi yang diajarkan, maka guru diharapkan mampu meng-upgrade diri untuk mengembangkan kompetensinya dan meningkatkan kreatifitasnya dalam memanfaatkan berbagai macam media pembelajaran guna meningkatkan kualitas pembelajaran. Hal ini dapat memacu siswa agar lebih aktif saat pembelajaran dan memunculkan daya pikir dan keinginan untuk mengetahui konsep-konsep yang terdapat dalam media pembelajaran tersebut.

Media pembelajaran merupakan salah satu komponen proses belajar mengajar yang memiliki peranan sangat penting dalam menunjang keberhasilan proses belajar mengajar hal tersebut selaras dengan Agustina, $R$ \& Sitompul, H (2015) menyatakan bahwa media merupakan komponen-komponen di lingkungan belajar peserta didik yang merangsang peserta didik untuk belajar dengan baik. Multimedia memadukan berbagai media untuk menyampaikan materi dengan terstruktur dan desain yang menarik sehingga merangsang peserta untuk belajar lebih tekun dan tidak mudah bosan karena adanya ilustrasi yang menarik. Sedangkan menurut Suryani, $\mathrm{N}$ (2016) menjelaskan bahwa penggunaan suatu media pembelajaran berbasis komputer mempunyai dampak yang tinggi terhadap minat siswa dalam mempelajari kompetensi yang akan diberikan. Penggunaan suatu media pembelajaran bisa mempersingkat waktu persiapan pembelajaran, meningkatkan semangat belajar siswa dan mengurangi ke tidak pahaman siswa saat mendapat penjelasan oleh guru. Kurniawan \& Tangkudung (2017) berpendapat bahwa disaat ini multimedia interaktif merupakan multimedia yang sangat diakui sebagai salah satu cara untuk dapat memecahkan suatu masalah pendidikan yang terjadi di negara maju dan juga di negara berkembang. Selain itu seiring berkembangnya waktu, kemajuan teknologi sangatlah cepat bahkan bisa di bilang sangat pesat, tentunya dengan kondisi seperti ini seorang guru diharapkan dapat memanfaatkan kemajuan teknologi dengan menggunakan multimedia interaktif dalam proses pembelajaran.

Articulate storyline adalah sebuah perangkat lunak atau software e-learning yang berfungsi untuk membuat media perangkat pembelajaran yang interaktif, fungsi articulate storyline sama dengan microsof power point. Articulate storyline merupakan alat yang digunakan untuk mempresentasikan informasi dengan tujuan tertentu (Pratama, R. A, 2018). Menurut hasil penelitian Purnama dan Asto (2014) menyatakan bahwa suatu pembelajaran interaktif menggunakan aplikasi articulate storyline dinyatakan baik dan layak digunakan untuk memacu siswa dalam mengikuti mata pelajaran teknik elektronika dasar di SMK Negeri 2 Probolinggo. Menurut penelitian Al Habib, S.A (2020) menyatakan bahwa suatu multimedia interaktif berbasis aplikasi articulate storyline dinyatakan sangat layak dan dapat digunakan secara teoritis dan dapat meningkatkan hasil belajar siswa.

Berdasarkan hasil penelitian sebelumnya terdapat keunggulan dari produk pengembangan articulate storyline yaitu dengan menggunakan Rencana Pelaksanaan Pembelajaran (RPP) gerak dasar lari, materi pembelajaran gerak dasar lari, video materi atau praktek pembelajaran gerak dasar lari kelas IV, dan evaluasi pembelajaran gerak dasar lari, bisa diakses melalui link dan bisa di unduh sebagai aplikasi android. Jika menggunakan komputer bisa diakses melalui link yang diberikan, sehingga memudahkan dan menjadi referensi mengajar guru mata pelajaran PJOK khususnya Sekolah Dasar (SD) dalam menyelenggarakan pembelajaran gerak dasar lari. Produk ini juga dapat digunakan jika sarana dan prasarana pembelajaran gerak 
dasar lari tidak memadai, serta dapat digunakan di dalam kelas sebelum praktek dilapangan. Selain itu, dengan adanya produk pengembangan ini diharapkan guru dapat membuat proses belajar mengajar yang menyenangkan dan menarik perhatian bagi siswa. Melalui pengembangan produk ini juga diharapkan dapat meningkatkan minat belajar siswa dan dapat memotivasi serta hasil belajar peserta didik agar lebih baik, sehingga pembelajaran gerak dasar berlari dapat mencapai tujuan yang diharapkan.

Dari hasil observasi awal penelitian di Kecamatan Wajak, Kabupaten Malang, peneliti melakukan analisis kebutuhan dengan menyebar angket google form terhadap anggota Kelompok Kerja Guru (KKG) PJOK SD, diperoleh hasil bahwa pembelajaran gerak dasar lari untuk jenjang Sekolah Dasar (SD) di Kecamatan wajak masih monoton dan proses pembelajaran belum memanfaatkan teknologi, sedangkan perangkat pembelajaran hanya menggunakan print out. Hal tersebut merupakan perangkat pembelajaran yang telah lama digunakan, selain itu belum adanya pengembangan perangkat pembelajaran gerak dasar lari berbasis aplikasi articulate storyline. Padahal fasilitas yang ada di setiap sekolah sudah memiliki alat penunjang seperti LCD, smartphone dan komputer untuk pembelajaran.

\section{METODE}

Penelitian pengembangan adalah penelitian dengan tujuan untuk menghasilkan produk yang dibutuhkan di masa kini. Selaras menurut Winarno, M. E (2013: 77) penelitian pengembangan adalah penelitian yang diupayakan untuk mengembangkan produk yang sesuai dengan kebutuhan. Rancangan penelitian pengembangan sangat membantu untuk memecahkan masalah yang ada dalam dunia pendidikan dan dalam proses pembelajaran. terutama dalam mata pelajaran pendidikan jasmani, olahraga dan kesehatan. Penelitian dan pengembangan perangkat pembelajaran gerak dasar lari berbasis aplikasi articulate storyline ini dengan menggunakan tahapan-tahapan seperti berikut: 1) analisis kebutuhan, 2) desain produk, 3) pengembangan produk, 4) implementasi, dan 5) evaluasi produk.

\section{Analisis}

Pada tahap analisis ini terdapat 2 bagian yaitu needs assesment dan front-end analysis. Pada tahap needs assesment yaitu pengumpulan data secara keseluruhan yang digunakan untuk bahan pengembangan perangkat pembelajaran gerak dasar lari berbasis aplikasi articulate storyline, dan pada tahap front-end analysis merupakan bagian untuk menganalisis data dan informasi yang dibutuhkan dalam penelitian dan pengembangan. Pada bagian front-end analysis penelitian ini terdapat beberapa data dan informasi yang dibutuhkan yaitu audience analysis yang berguna untuk memilih sasaran yang nantinya menggunakan pengembangan perangkat pembelajaran gerak dasar lari berbasis aplikasi articulate storyline berupa hardware atau software, media analysis berguna dalam penentuan jenis media yang akan digunakan dalam pengembangan, serta extand-data analysis berguna untuk memilih isi materi yang akan dipakai dalam perangkat pembelajaran gerak dasar lari berbasis aplikasi articulate storyline. Analisis adalah tahapan yang digunakan menjabarkan situasi lapangan yang bertujuan untuk mengetahui produk pengembangan apakah bisa diterapkan atau tidak oleh subjek.

\section{Desain}

Tahap desain adalah tahapan dalam merancang produk pengembangan perangkat pembelajaran gerak dasar laari berbasis aplikasi articulate storyline berdasarkan dari pengetahuan yang diperoleh dari tahap analisis yang terdiri dari material collecting atau mengumpulkan bahan yang didapatkan untuk kebutuhan yang digunakan dalam pengembangan produk pengembangan perangkat pembelajaran gerak dasar lari berbasis aplikasi articulate storyline, menyusun storyboard dan membuat flowchart.

\section{Pengembangan}

Tahap pengembangan adalah tahapan yang akan peneliti lakukan untuk mengembangkan perangkat pembelajaran gerak dasar lari berbasis aplikasi articulate storyline sesuai menurut desain yang sudah dibuat dan dirancang, terdapat beberapa tahapan dalam pengembangan yaitu 1) pengembangan, 2) validasi, dan 3) revisi. Pada tahapan pengembangan ini meliputi pengembangan interface, coding, testing, publising dan pemaketan. Pada tahapapan validasi yaitu dilakukan oleh ahli pembelajaran, ahli permainan SD, ahli pendidikan jasmani, olahraga dan kesehatan, ahli media, dan ahli atletik agar produk aplikasi articulate 
storyline dapat diperbaiki. Pada tahapan revisi dilakukan dengan melihat hasil berdasarkan saran serta masukan yang uraikan oleh para ahli sehingga dapat menciptakan produk yang baik dan berguna.

\section{Implementasi}

Tahap implementasi adalah tahap uji coba yang akan melibatkan guru mata pelajaran pendidikan jasmani, kesehatan dan olahraga yang tergabung dalam Kelompok Kerja Guru (KKG) PJOK SD di Kecamatan Wajak. Tujuan tahap implementasi ini adalah untuk mengukur tanggapan dan penilaian terhadap produk pengembangan perangkat pembelajaran gerak dasar lari berbasis aplikasi articulate storyline yang telah dikembangkan oleh peneliti yang nantinya dinilai dari beberapa aspek dengan menyebar angket penilaian yang berguna untuk memperbaiki produk.

\section{Evaluasi}

Pada tahap ini merupakan tahapan evaluasi yang dilakukan setelah memperoleh saran dan masukan dari para ahli yang meliputi ahli pembelajaran, ahli permainan SD, ahli pendidikan jasmani, olahraga dan kesehatan, ahli media, dan ahli atletik dan uji coba yang sudah dilakukan kepada Kelompok Kerja Guru (KKG) PJOK SD. Hal tersebut bertujuan untuk mengetahui tingkat kelayakan produk pengembangan perangkat pembelajaran gerak dasar lari berbasis aplikasi articulate storyline yang telah dikembangkan oleh peneliti dan nantinya akan dijabarkan kekurangan dan kelebihan serta spesifikasi produk pengembangan perangkat pembelajaran gerak dasar lari berbasis aplikasi articulate storyline.

Uji coba produk bertujuan untuk memperoleh data yang digunakan sebagai dasar dalam menentukan kelayakan produk pengembangan perangkat pembelajaran gerak dasar lari. Dalam ujicoba produk terdapat beberapa hal yang perlu diperhatikan yaitu: (1) Desain untuk uji coba, (2) Subyek yang digunakan uji coba, (3) Jenis data yang digunakan, (4) Membuat instrument uji coba, dan (5) Cara analisis data.

\section{Desain Uji Coba}

Desain uji coba ini terdapat evaluasi berupa saran dan masukan dari para ahli yang meliputi ahli pembelajaran, ahli permainan SD, ahli Pendidikan Jasmani, Olahraga dan Kesehatan, ahli media, dan ahli atletik dan uji coba kelompok kecil KKG PJOK Sekolah Dasar dan uji coba kelompok besar KKG PJOK Sekolah Dasar. Nantinya saran dan masukan dari para ahli yang akan digunakan peneliti dalam memperbaiki produk awal pengembangan yang sudah dirancang dan dibuat oleh peneliti.

\section{Evaluasi Ahli}

Dalam tahap evaluasi ahli akan melibatkan 5 ahli yaitu, (1) ahli pembelajaran yaitu, Frendy Aru Fantiro, M. Pd, (2) ahli permainan SD yaitu, Ndaru Kukuh Masgumelar, S.Pd., M.Pd, (3) ahli Pendidikan Jasmani, Olahraga dan Kesehatan yaitu, Irin Dwi Agustina, S.Pd (4) ahli media yaitu, Eka Pramono, S.I.P, M.Si. (5) ahli atletik yaitu, Mujianto, S.Pd.

\section{Uji Coba I}

Dalam uji coba I produk ini akan melibatkan 8 guru PJOK SD yang tergabung dalam Kelompok Kerja Guru (KKG) Sekolah Dasar mata pelajaran pendidikan jasmani, kesehatan dan olahraga di Kecamatan Wajak.

\section{Uji Coba II}

Dalam uji coba II produk ini akan melibatkan 15 guru PJOK SD yang tergabung dalam Kelompok Kerja Guru (KKG) Sekolah Dasar mata pelajaran pendidikan jasmani, kesehatan dan olahraga di Kecamatan Wajak.

\section{Subyek Uji Coba}

Dalam penelitian uji coba, subyek yang terlibat dalam penelitian pengembangan produk ini meliputi: (1) Subyek uji coba kelompok kecil melibatkan 8 guru PJOK SD di kecamatan Wajak Kabupaten Malang, (2) subyek uji coba kelompok besar melibatkan 15 guru PJOK SD di kecamatan Wajak Kabupaten Malang, (3) Subyek evaluasi dari para ahli yang meliputi, 1 ahli pembelajaran, 1 ahli permainan sekolah dasar , 1 ahli Pendidikan Jasmani, Olahraga dan Kesehatan, 1 ahli media, dan 1 ahli atletik. 


\section{Jenis Data}

Data dalam penelitian ini adalah diperoleh dari penilaian para ahli, dan data dari uji lapangan berupa kualitatif dan kuantitatif. Data kualitatif didapat dari saran serta masukan para ahli. Sedangkan data kuantitatif didapat dari hasil uji coba I dan hasil dari uji coba II yang berupa angka.

\section{Instrumen Pengumpulan Data}

Data yang diperoleh dalam penelitian ini adalah dari tinjauan para ahli dan hasil uji lapangan berupa kualitatif dan kuantitatif. Data kualitatif didapat berupa saran dan masukan para ahli. Sedangkan data kuantitatif didapat dari uji coba kelompok kecil dan uji coba kelompok besar.

\section{Teknik Analisis Data}

Teknik analisis data merupakan tahap yang digunakan dalam mengolah data. Penelitian dan pengembangan produk ini menggunakan statistik deskriptif untuk mengolah data. Teknik pengukuran yang dilakukan untuk mengumpulkan data dengan menggunakan skala likert, tujuannya adalah untuk mengukur sikap, pendapat seseorang dan persepsi atau sekelompok orang tentang fenomena sosial (Sugiyono, 2017: 134).

Dalam instrumen skala likert memiliki kategori tingkatan jawaban dari kategori sangat baik sampai sangat buruk. Agar mudah dalam menganalisis data kuantitatif jawaban sebaiknya diberi skor yang telah ditetapkan yaitu satu (1) dua (2) tiga (3) dan (4) skala penilaian likert.

Tabel 2. Penilaian Skala untuk Pernyataan Positif

\begin{tabular}{clcc}
\hline No. & Keterangan & Jawaban & Skor Positif \\
\hline 1. & Sangat Setuju & $\mathrm{A}$ & 4 \\
2. & Setuju & $\mathrm{B}$ & 3 \\
3. & Ragu-ragu & $\mathrm{C}$ & 2 \\
4. & Tidak Setuju & $\mathrm{D}$ & 1 \\
\hline
\end{tabular}

Rumus dalam mendapatkan data berbentuk deskriptif kuantitatif dengan persentase yang dikatakan Akbar \& Sriwiyana, di bawah ini:

$$
\mathrm{V}=\frac{\mathrm{TSEV}}{\mathrm{S}-\max } \times 100 \%
$$

\section{Keterangan:}

V : Validitas

TSEV : Total skor empirik validator

S-max : Skor maksimal yang diharapkan

$100 \%$ : Bilangan konstanta

Kemudian sebagai memudahkan pada bagian ketepatan data hasil menganalisis persentase dapat dikaitkan pada persentase yang telah didapatkan. Penggolongan kategorisasi persentase yaitu:

Tabel 3. Parameter Status Produk (Irawan dan Japarianto 2013)

\begin{tabular}{ccc}
\hline persentase & Kategori & Keterangan \\
\hline $75,01 \%-100,00 \%$ & Sangat Valid & Dapat dipakai tanpa revisi \\
$50,01 \%-75,00 \%$ & Cukup Valid & Dapat dipakai dengan revisi \\
$25,01 \%-50,00 \%$ & Tidak Valid & Tidak dapat dipakai \\
$00,00 \%-25,00 \%$ & Sangat Tidak Valid & Terlarang dipakai \\
\hline
\end{tabular}

\section{HASIL}

Hasil penelitian dalam artikel ini memaparkan mengenai analisis data yang berasal dari beberapa ahli atau pakar diantaranya yaitu pakar pembelajaran, pakar permainan sekolah dasar, pakar pendidikan jasmani olahraga dan kesehatan, ahli media, ahli atletik, dan data hasil uji coba dari kelompok kecil maupun kelompok besar. Hasil dari analisis data yang dikumpulkan mengacu pada segi ketepatan, kejelasan, dan kemudahan 
dari produk pengembangan perangkat pembelajaran gerak dasar lari berbasis aplikasi articulate storyline dan disajikan dalam tabel dibawah:

Tabel 4. Hasil Data Analisis Ahli Pembelajaran

\begin{tabular}{cccc}
\hline No & Aspek & $\%$ & Kategori \\
\hline 1 & Kejelasan & 90 & Sangat Valid \\
2 & Ketepatan & 92 & Sangat Valid \\
3 & Kemudahan & 100 & Sangat Valid \\
\hline & Rata-Rata & $\mathbf{9 4}$ & Sangat Valid \\
\hline
\end{tabular}

Mengacu pada segi kejelasan, ketepatan, kemudahan, kemenarikan serta kesesuaian, sehingga didapatkan analisis data yang dipaparkan melalui produk pengembangan perangkat pembelajaran gerak dasar lari berbasis aplikasi articulate storyline dan disajikan dalam tabel di bawah:

Tabel 5. Hasil Data Analisis Ahli Permainan Sekolah Dasar

\begin{tabular}{|c|c|c|c|}
\hline No & Aspek & $\%$ & Kategori \\
\hline 1 & Kejelasan & 94 & Sangat Valid \\
\hline 2 & Kemudahan & 100 & Sangat Valid \\
\hline 3 & Kemenarikan & 100 & Sangat Valid \\
\hline 4 & Kesesuian & 100 & Sangat Valid \\
\hline \multirow[t]{2}{*}{5} & Ketepatan & 89 & Sangat Valid \\
\hline & Rata-Rata & 96 & Sangat Valid \\
\hline
\end{tabular}

Mengacu pada segi kejelasan, ketepatan, kemudahan, kemenarikan serta kesesuaian, sehingga didapatkan analisis data yang dipaparkan melalui produk pengembangan perangkat pembelajaran gerak dasar lari berbasis aplikasi articulate storyline dan disajikan dalam tabel di bawah:

Tabel 6. Hasil Data Analisis Ahli PJOK

\begin{tabular}{|c|c|c|c|}
\hline No & Aspek & $\%$ & Kategori \\
\hline 1 & Kejelasan & 87 & Sangat Valid \\
\hline 2 & Kemudahan & 100 & Sangat Valid \\
\hline 3 & Kemenarikan & 100 & Sangat Valid \\
\hline 4 & Kesesuaian & 75 & Cukup Valid \\
\hline \multirow[t]{2}{*}{5} & Ketepatan & 86 & Sangat Valid \\
\hline & Rata-Rata & 90 & Sangat Valid \\
\hline
\end{tabular}

Mengacu pada segi kejelasan, kelengkapan, ketepatan, kemudahan, kemenarikan serta kesesuaian, sehingga didapatkan analisis data yang dipaparkan melalui produk pengembangan perangkat pembelajaran gerak dasar lari berbasis aplikasi articulate storyline dan disajikan dalam tabel di bawah:

Tabel 7. Hasil Data Analisis Ahli Media

\begin{tabular}{|c|c|c|c|}
\hline No & Aspek & $\%$ & Ketegori \\
\hline 1 & Kejelasan & 100 & Sangat Valid \\
\hline 2 & Kelengkapan & 100 & Sangat Valid \\
\hline 3 & Kemudahan & 100 & Sangat Valid \\
\hline 4 & Kemenarikan & 96 & Sangat Valid \\
\hline 5 & Kesesuaian & 95 & Sangat Valid \\
\hline 6 & Ketepatan & 87 & Sangat Valid \\
\hline & Rata-Rata & 96 & Sangat Valid \\
\hline
\end{tabular}


Mengacu pada segi kejelasan, ketepatan, kemudahan, kemenarikan serta kesesuaian, sehingga didapatkan analisis data yang dipaparkan melalui produk pengembangan perangkat pembelajaran gerak dasar lari berbasis aplikasi articulate storyline dan disajikan dalam tabel di bawah:

Tabel 8. Hasil Data Analisis Ahli Atletik

\begin{tabular}{clcl}
\hline No & Aspek & $\%$ & Kategori \\
\hline 1 & Kejelasan & 88 & Sangat Valid \\
2 & Kemudahan & 100 & Sangat Valid \\
3 & Kemenarikan & 100 & Sangat Valid \\
4 & Kesesuaian & 87 & Sangat Valid \\
5 & Ketepatan & 89 & Sangat Valid \\
\hline & Rata-Rata & $\mathbf{9 3}$ & Sangat Valid \\
\hline
\end{tabular}

Hasil data dari uji kelompok kecil Mengacu pada segi kejelasan, kegunaan, kemudahan, kemenarikan serta kesesuaian, sehingga didapatkan analisis data yang dipaparkan melalui produk pengembangan perangkat pembelajaran gerak dasar lari berbasis aplikasi articulate storyline dan disajikan dalam tabel di bawah:

Tabel 9. Hasil Data Analisis Uji Kelompok Kecil Kelompok Kerja Guru (KKG) PJOK SD

\begin{tabular}{clll}
\hline No & \multicolumn{1}{c}{ Aspek } & $\%$ & Kategori \\
\hline 1 & Kejelasan & 92 & Sangat Valid \\
2 & kemudahan & 86 & Sangat Valid \\
3 & Kemenarikan & 90 & Sangat Valid \\
4 & Kesesuaian & 88 & Sangat Valid \\
5 & Kegunaan & 89 & Sangat Valid \\
\hline & Rata-Rata & $\mathbf{8 9}$ & Sangat Valid \\
\hline
\end{tabular}

Hasil data dari uji kelompok besar Mengacu pada segi kejelasan, kegunaan, kemudahan, kemenarikan serta kesesuaian, sehingga didapatkan analisis data yang dipaparkan melalui produk pengembangan perangkat pembelajaran gerak dasar lari berbasis aplikasi articulate storyline dan disajikan dalam tabel di bawah:

Tabel 10. Hasil Analisis Data Uji Kelompok Besar Kelompok Kerja Guru (KKG) PJOK SD

\begin{tabular}{clll}
\hline No & \multicolumn{1}{c}{ Aspek } & $\%$ & kategori \\
\hline 1 & Kejelasan & 86 & Sangat Valid \\
2 & Kemudahan & 87 & Sangat Valid \\
3 & Kemenarikan & 86 & Sangat Valid \\
4 & Kesesuian & 88 & Sangat Valid \\
5 & Kegunaan & 89 & Sangat Valid \\
\hline & Rata-Rata & $\mathbf{8 6}$ & Sangat Valid
\end{tabular}

\section{PEMBAHASAN}

Produk pengembangan ini merupakan pengembangan perangkat pembelajaran gerak dasar lari berbasis aplikasi articulate storyline yang terdapat: video, teks, dan suara. Menurut Sapitri, D dan Bentri, A, (2020) menjelaskan bahwa articulate storyline sebuah perangkat yang beroleh dipakai untuk menyusun presentasi. Memegang kedudukan yang sama dengan microsoft power point, articulate storyline terdapat keunggulan presentasi yang lebih komprehensi dan kreatif. Software ini juga mempunyai fitur seperti timeline, movie, picture, character dan lain lain yang mudah digunakan. articulate storyline merupakan salah satu multimedia authoring tools yang bisa dipakai untuk menciptakan perangkat pembelajaran yang saling berinteraksi dengan isi yang dibentuk dari gabungan teks, gambar, grafik, suara, animasi, dan video. Hal tersebut selaras dengan Arwanda, Irianto, dan Andriani (2020) menyatakan media pembelajaran articulate storyline merupakan salah satu media pembelajaran yang sengaja dibuat untuk mengemas sebuah pembelajaran, pemanfaatan articulate storyline sebagai media pembelajaran melibatkan peserta didik langsung, sehingga peserta didik 
akan terlibat aktif dalam pembelajaran. Sehingga aplikasi articulate storyline ini masuk kedalam suatu media pembelajaran yang berpengaruh positif sebagai sarana dalam menyampaikan pembelajaran di sekolah, yang nantinya produk pengembangan perangkat pembelajaran gerak dasar lari berbasis aplikasi articulate storyline ini berupa perangkat pembelajaran gerak dasar lari dalam bentuk aplikasi android yang pastinya menarik dan dapat dibawa kemana saja. Hal tersebut selaras dengan pendapat Ekayani, P (2017) bahwa media pembelajaran merupakan suatu alat yang digunakan dalam mendorong perhatian serta kemampuan seseorang untuk dapat termotivasi dalam proses pembelajaran sehingga dapat terselenggara kegiatan belajar mengajar yang efektif dan efisien. Dengan begitu guru akan menyadari bahwa tanpa adanya media pembelajaran yang inovatif, materi pembelajaran akan sulit untuk dapat dicerna dan dipahami oleh peserta didik, apalagi bila materi pembelajaran yang harus disampaikan tergolong rumit dan kompleks. Untuk itu perlu adanya pengembangan media pembelajaran yang inovatif agar materi dapat sampai ke peserta didik secara efektif dan efisien dan dapat membantu peserta didik dalam memahami suatu informasi sehingga peserta didik dapat lebih mudah untuk menguasai keterampilan yang akan dipelajarinya dalam pembelajaran. Hal tersebut sependapat dengan Leow, F,T and Neo, M (2014) menyatakan bahwa pembelajaran yang dilakukan secara inovatif, salah satunya dengan memanfaatkan konten media pembelajaran yang dapat melibatkan siswa, tanpa disadari akan meningkatkan motivasi dan semangat siswa dalam proses pembelajaran yang tentunya akan sangat membantu dan berpengaruh pada hasil belajar siswa. Sehingga produk pengembangan berbasis aplikasi articulate storyline ini termasuk dalam media yang memiliki pengaruh positif sebagai media pembelajaran di sekolah. Apalagi bentuk akhir dari produk pengembangan perangkat pembelajaran gerak dasar lari ini berbasis aplikasi articulate storyline yang dikemas dalam bentuk aplikasi yang nantinya berupa link dan bisa di akses di smartphone dan laptop secara online maupun offline, dan bisa di unduh di aplikasi android sehingga mudah dibawa kemana saja. Kemudian produk pengembangan berbasis aplikasi articulate storyline ini berisi rencana pelaksanaan pembelajaran, kompetensi inti dan kompetensi dasar gerak dasar lari kelas IV, materi pembelajaran gerak dasar lari, video materi pembelajaran gerak dasar lari kelas IV, evaluasi penilaian, dan biodata penulis yang dikemas berbasis aplikasi.

Pada produk pengembangan ini tidak hanya berbasis aplikasi articulate storyline akan tetapi juga lebih dioptimalkan di pembelajaran gerak dasar lari kelas IV yang dikemas dalam video materi pembelajaran. Produk pengembangan ini juga bisa dijadikan sebagai media pembelajaran di dalam kelas sebelum dilakukan praktik kegiatan inti di lapangan, dan juga bisa menjadi solusi bagi guru jika sarana dan prasarana olahraga di sekolah mereka mengajar kurang memadai, sehingga guru tetap bisa menyampaikan materi pembelajaran ke peserta didik dengan efisien dan menarik. Video materi pembelajaran yang diberikan dalam pembelajaran gerak dasar lari berbasis aplikasi articulate storyline ini dapat membantu guru pendidikan jasmani dan kesehatan dalam memberikan materi gerak dasar lari dikarenakan materi pembelajaran yang termuat dalam aplikas ini mengandung unsur gerak dasar lari yang memiliki indikator yaitu gerak dasar lari yaitu perkembangan dari gerakan berjalan. Gerakan dasar anggota tubuh pada saat berlari menyerupai gerakan berjalan. Perbedaanya terletak pada irama ayunan langkah, pada lari iramanya lebih cepat dan ada saat-saat melayang. Hal tersebut sependapat dengan Maelani, W dan Mustara, S.S (2020) lari merupakan frekuensi langkah yang di cepatkan sehingga pada waktu berlari ada kecenderungan badan melayang, yang artinya pada waktu lari kedua kaki tidak menyentuh tanah sekurang-kurangnya satu kaki tetap menyentuh tanah . Lari adalah gerakan dasar mengais badan yang bergerak maju karena adanya akibat dari gaya dorong ke belakang terhadap tanah. Hal tersebut selaras dengan Semakur (2020) menyatakan bahwa keterampilan gerak dasar berlari dapat diartikan sebagai kemampuan untuk melaksanakan tugas-tugas gerak lari secara baik dan benar. Olahraga lari juga sudah diajarkan sejak SD bahkan sudah sering diperlombakan. Pada dasarnya struktur dan karakteristik pola gerak dalam atletik terdapat pada tiga hal pokok, yaitu (1) lari termasuk jalan, (2) lompat, dan (3) lempar.

Berdasarkan hasil uji validasi ahli pembelajaran diperoleh persentasi sebesar $94 \%$, hasil uji validasi ahli permainan Sekolah Dasar diperoleh persentasi sebesar 96\%, hasil uji validasi ahli Pendidikan Jasmani, Olahraga dan Kesehatan diperoleh persentasi sebesar 90\%, hasil uji validasi ahli media diperoleh persentasi sebesar $96 \%$, hasil uji validasi ahli atletik diperoleh persentasi sebesar $93 \%$, hasul uji coba kelompok kecil diperoleh persentasi sebesar $89 \%$, hasil uji coba kelompok besar diperoleh persentasi sebesar $86 \%$, dan artinya keseluruhan hasil uji validasi oleh beberapa ahli dan saat uji coba produk pada kelompok kecil serta kelompok besar untuk produk articulate storyline mendapatkan hasil kriteria sangat valid dan layak digunakan. Diharapkan dalam pembelajaran gerak dasar lari guru mampu memanfaatkan teknologi yang ada dan memberikan media pembelajaran yang modern, sehingga dapat meningkatkan minat belajar peserta didik 
serta menambah referensi guru dalam proses pembelajaran mata pelajaran pendidikan jasmani olahraga dan kesehatan. Hal tersebut selaras dengan Rahman, Z, dkk (2020) menyatakan dari hasil penelitian menunjukkan bahwa produk pembelajaran kebugaran jasmani unsur kecepatan berbasis multimedia interaktif di SMA Negeri 1 Turen layak digunakan karena siswa lebih aktif dan sangat antusias dalam mengikuti pelajaran dalam materi kebugaran jasmani unsur kecepatan dengan menggunakan multimedia interaktif meggunakan audio visual. dan juga dapat menjadi referensi sumber belajar terutama mata pelajaran pendidikan jasmani olahraga dan kesehatan. Sedangkan menurut Manulu, D.L, dkk, (2020) menyatakan dari hasil penelitiannya bahwa pengembangan latihan kekuatan berbasis multimedia interaktif menggunakan Autoplay Media Studio, latihan beban yang dikembangkan dapat digunakan sebagai alat untuk meningkatkan kekuatan mahasiswa pendidikan kepelatihan olahraga pada pembelajaran matakuliah spesialisasi kondisi fisik dasar karena memiliki kesesuaian, ketepatan, kemenarikan, dan kemudahan untuk dipelajari, dikuasai, dan di praktikkan.

\section{KESIMPULAN}

Dari hasil pengembangan dan penelitian produk pembelajaran gerak dasar lari berbasis aplikasi articulate storyline, maka dapat disimpulkan bahwa produk pengembangan gerak dasar lari berbasis aplikasi articulate storyline layak digunakan dalam pembelajaran gerak dasar lari untuk kelas IV dan dapat dijadikan sebagai penunjang pembelajaran pada mata pelajaran Pendidikan Jasmani dan Kesehatan kelas IV SD untuk materi pembelajaran gerak dasar lari.

\section{DAFTAR PUSTAKA}

Adi, S., \& Fathoni, A. F. (2019). Development of Learning Model Based on Blended Learning in Sports School. https://doi.org/10.2991/acpes-19.2019.2

Adi, S., \& Fathoni, A. F. (2020). Blended Learning Analysis for Sports Schools in Indonesia. International Journal of Interactive Mobile Technologies (iJIM), 14(12), 149-164. Retrieved from https://www.onlinejournals.org/index.php/i-jim/index

Adi, S., \& Fathoni, A. F. (2020). Mobile Learning sebagai Fasilitas Belajar Mandiri Pembelajaran Senam Lantai pada Mahasiswa Jurusan IImu Keolahragaan. Jurnal Pendidikan: Teori, Penelitian, Dan Pengembangan, 5(8), 1158-1166. Retrieved from http://journal.um.ac.id/index.php/jptpp/article/view/13946/6206

Adi, S., \& Fathoni, A. F. (2020). The effectiveness and efficiency of blended learning at sport schools in Indonesia. International Journal of Innovation, Creativity and Change.

Al Habib, S.A. (2020). Potensi Penggunaan Articulate Storyline 3.6 Berbasis E-Learning Terhadap Hasil Belajar Mata Pelajaran Biologi Tingkat SMA Di Era Industri 4.0.

Aryadi, D. \& Daulay, D.E. (2019). Pembelajaran Gerak Dasar Lari Melalui Permainan. Jurnal Prestasi 3(6), 87-92.

Christianto, J., \& Dwiyogo, W. D. (2020). Pengembangan Media Pembelajaran Cricket Berbasis Mobile Learning Pada Tim Olahraga Cricket Universitas Negeri Malang. Gelanggang Pendidikan Jasmani Indonesia, 3(2), 168. https://doi.org/10.17977/um040v3i2p168-174

Dwiyogo, W. D., \& Radjah, C. L. (2020). Effectiveness, efficiency and instruction appeal of blended learning model. International Journal of Online and Biomedical Engineering, 16(4), 91-108. https://doi.org/10.3991/ijoe.v16i04.13389

Ekayani, P. (2017). Pentingnya penggunaan media pembelajaran untuk meningkatkan prestasi belajar siswa. Jurnal Fakultas IImu Pendidikan Universitas Pendidikan Ganesha Singaraja, 2(1), 1-11.

Fathoni, A. F. (2018). The Role of Blended Learning on Cognitive Step in Education of Sport Teaching by Adjusting the Learning Style of the Students. https://doi.org/10.2991/isphe-18.2018.49

Irawan, D. \& Japarianto, E. (2013). Analisa Pengaruh Kualitas Produk Terhadap Loyalitas Melalui Kepuasan Sebagai Variabel Intervening Pada Pelanggan Restoran Por Kee Surabaya. Jurnal Manajemen 
Pemasaran.

Kurniawan, A.W.,\& Tangkudung, J. (2017). Development Of Interactive Multimedia-Based Gymnastics Floor Techniques Learning Model For Junior High School Students. Journal Of Indonesian Physical Education And Sport 3(1), 100-115.

Kristiono, I. D., Dwiyogo, W. D., \& Hariadi, I. (2019). Pembelajaran IImu Gizi Olahraga Berbasis Blended Learning pada Mahasiswa Pendidikan Jasmani, Kesehatan, dan Rekreasi. Jurnal Pendidikan: Teori, Penelitian, Dan Pengembangan, 4(2), 235-241. Retrieved from http://journal.um.ac.id/index.php/jptpp/article/view/12004

Kurniawan, R., Winarno, M. E., \& Dwiyogo, W. D. (2018). Evaluasi Pembelajaran Pendidikan Jasmani, Olahraga, dan Kesehatan pada Siswa SMA Menggunakan Model Countenance. Jurnal Pendidikan: Teori, Penelitian, Dan Pengembangan, 3(10), 1-12. Retrieved from http://journal.um.ac.id/index.php/jptpp/article/view/11599

Leow, F,T., \& Neo, M. (2014). Interactive Multimedia Learning: Innovating Classroom Education In A Malaysian University. The Turkish Online Journal Of Educational Technology 13(2), 99-100.

Maelani, W, \& Mustara, S.S. (2020). Model Pembelajaran Gerak Dasar Lari Berbasis Permainan Tematik Pada Siswa Tunagrahita Ringan. Jurnal Pendidikan Jasmani dan Adaptif 2(3), 41-52.

Manulu, D.L, dkk. (2020). Pengembangan Multimedia Interaktif Latihan Kekuatan Pada Matakuliah Spesialisasi Kondisi Fisik Dasar Untuk Mahasiswa Pendidikan Kepelatihan Olahraga Fakultas IImu Keolahragaan. Jurnal Sport Science and Health 2(1), 49-57.

Masgumelar, N. K., Dwiyogo, W. D., \& Nurrochmah, S. (2019). Modifikasi Permainan menggunakan Blended Learning Mata Pelajaran Pendidikan Jasmani, Olahraga, dan Kesehatan. Jurnal Pendidikan: Teori, Penelitian, Dan Pengembagan, 4(7), 979-986. Retrieved from http://journal.um.ac.id/index.php/jptpp/article/view/12645

Mustafa, P.S. \& Dwiyogo, W.D. (2020). Kurikulum Pendidikan Jasmani, Olahraga, dan Kesehatan di Indonesia Abad 21. Jurnal Riset Teknologi dan Inovasi Pendidikan (JARTIKA) 3(2), 422-438.

Pahliwandari, R. (2017). Penerapan Teori Pembelajaran Kognitif dalam Pembelajaran Pendidikan Jasmani dan Kesehatan. Jurnal Pendidikan Olahraga 5(2), 154-164.

Pambudi, M. I., Winarno, M., \& Dwiyogo, W. D. (2019). Perencanaan dan Pelaksanaan Pembelajaran Pendidikan Jasmani Olahraga Kesehatan. Jurnal Pendidikan Olahraga, Universitas Negeri Malang, 4(1), 110-116. Retrieved from http://journal.um.ac.id/index.php/jptpp/

Permendikbud No 37 Tahun 2018 KI-KD SD SMP SMA.

Pratama, R. A. (2018). Media Pembelajaran Berbasis Articulate Storyline 2 Pada Materi Menggambar Grafik Fungsi Di Smp Patra Dharma 2 Balikpapan Learning Media Based On Articulate Storyline 2 On Drawing Function Graphs Lesson In Smp Patra Dharma 2 Balikpapan. Jurnal Dimensi 7(1), 19-35.

Priankalia Arwanda, Sony Irianto, \& Ana Andriani. (2020). Pengembangan media pembelajaran Articulate Storyline Kurikulum 2013 Berbasis Kompetensi Peserta Didik Abad 21 Tema 7 Kelas IV Sekolah Dasar. Jurnal IImiah Pendidikan Madrasah Ibtidaiyah 4(2), 194-204.

Purnama, S. I, Asto, I. G. P. B. (2014). Pengembangan Media Pembelajaran Interaktif Menggunakan Software Articulate Storyline Pada Mata Pelajaran Teknik Elektronika Dasar Kelas X Tei 1 Di Smk Negeri 2 Probolinggo. Jurnal Pendidikan Teknik Elektro 3(2), 257-279.

Rahman, Z, Kurniawan, A. W, \& Heynoek, F. P. (2020). Pengembangan Pembelajaran Kebugaran Jasmani Unsur Kecepatan Berbasis Multimedia Interaktif. Jurnal Sport Science and Health 2(1), 78-92.

Rena Agustina, Harun Sitompul. (2015). Pengaruh Media Pembelajaran dan Gaya Belajar Terhadap Hasil Belajar Biologi. Jurnal Teknologi Informasi \& Komunikasi dalam Pendidikan 2(1), 1-14.

Rodriquez, E. I. S., Dwiyogo, W. D., \& Supriyadi. (2020). Blended Learning Matakuliah Sepakbola untuk Mahasiswa Pendidikan Jasmani Kesehatan dan Rekreasi. Jurnal Pendidikan: Teori, Penelitian, Dan Pengembagan, 5(2), 206-213. 
Sapitri, D, Bentri, A. (2020). Pengembangan Media Pembelajaran Berbasis Aplikasi Articulate Storyline Pada Mata Pelajaran Ekonomi Kelas X SMA. Jurnal Inovtech 2(1), 56-62.

Semakur, Y. (2020). Pendekatan Bermain Dalam Pembelajaran Pendidikan Jasmani Untuk Meningkatkan Motivasi Belajar Gerak Dasar Lari Pada Siswa Kelas V Sd Katolik 041 Talibura. Jurnal Ekonomi, Sosial \& Humaniora 1(11), 1-8.

Sugiyono. (2017). Metode Penelitian Kuantitatif Kualitatif dan R\&D. Bandung: Alfabeta.

Suryani, N. (2016). Pengembangan media pembelajaran sejarah berbasis it. Jurnal Sejarah dan Budaya 10(02), 186-192.

Winarno, M. E. (2013). Metodologi Peneltian dalam Pendidikan Jasmani. Malang: Universitas Negeri Malang. 